\title{
The prevalence of Cryptosporidium spp. in lambs and goat kids in Kurdistan, I ran
}

\author{
Mohammad Khezri ${ }^{1}$ and Orkideh Khezri ${ }^{2}$
}

1. Department of Veterinary, Agricultural and Natural Resources Research Center of Kurdistan, Kurdistan, Iran; 2. Student of Medicine, School of Medicine, Shahid Beheshti University, Tehran, Iran

Corresponding author: Mohammad Khezri, email: khezri1836@yahoo.com

Received: 09-09-2013, Revised: 29-10-2013, Accepted: 05-11-2013, Published online: 08-12-2013

doi: $10.14202 /$ vetworld.2013.964-977

How to cite this article: Khezri M and Khezri O (2013) The prevalence of Cryptosporidium spp. in lambs and goat kids in Kurdistan, Iran, Veterinary World 6(12): 974-977.

\begin{abstract}
Aim: Cryptosporidium is a protozoan parasite that causes diarrhea, which is typically a short-lasting benign infection. The aim of the present study was to determinate the prevalence of Cryptosporidium infection in lambs and goat kids in Kurdistan district, Iran.

Materials and Methods: A total of 1200 fecal samples were obtained from diarrheic and non-diarrheic lambs and goat kids aged 1 to 6 months from 48 villages in the Kurdistan province, west of Iran. The samples were tested for the presence of Cryptosporidium spp. oocysts using modified Ziehl-Neelsen staining method.

Results: Cryptosporidium spp. oocysts were present in $10.24 \%$ of lambs and in $18.86 \%$ of goat kids. Both diarrhea and Cryptosporidium spp. oocysts were observed in $64.37 \%$ (56/87) of lambs and in $30.51 \%(18 / 59)$ of goat kids. Cryptosporidium spp. infection rates were significantly higher in diarrheic than in non-diarrheic groups. The highest rate of infection was found in an animal aged one month. Furthermore, the prevalence of the infection according to age groups and consistency of feces was found to be statistically significant.
\end{abstract}

Conclusion: The presence of Cryptosporidium spp. in lambs and goat kids in Kurdistan indicates that this protozoan parasite should also be considered in the etiology of lambs and goat kids exhibiting diarrhea.

Key words: Cryptosporidium spp., lambs, goat kids, prevalence, Iran

\section{I ntroduction}

Cryptosporidium is an apicomplexan intestinal protozoan, which infects the gastrointestinal tract of domestic animals and humans [1]. There are currently 16 recognized species of Cryptosporidium, which have been isolated from a large variety of hosts which include all the five groups [including Amphibians, Fishes, Reptiles, Birds, Mammals] of vertebrates [2]. Transmission occurs through the fecal-oral route, following direct contact with Cryptosporidium oocysts via person-to-person, zoonotic, waterborne, foodborne or airborne contact [3]. Most of the data on the prevalence of cryptosporidial infection in farm animals is related to cattle. In comparison, there is very less information on the occurrence of cryptosporidiosis in sheep and goats [4]. Cryptosporidiosis was first described in lambs with diarrhea in Australia, but no causative role could be ascribed to the organism because of the coincidental infections with pathogenic bacteria. Its role as a primary etiological agent of diarrhea in lambs was confirmed in the early 1980s in the studies on natural and experimental infections [5, 6]. In goats, infection with Cryptosporidium spp. is very important for the economy not only because of the

Copyright: The authors. This article is an open access article licensed under the terms of the Creative Commons Attribution License (http://creativecommons.org/licenses/by/2.0) which permits unrestricted use, distribution and reproduction in any medium, provided the work is properly cited. financial losses, but also in terms of health, due to the zoonotic nature of the disease. Since then, the parasitic infections in lambs and goat kids with and without diarrhea have been reported from many parts of the world [7]. Methods to detect Cryptosporidium spp. in feces usually involve microscopic examination of stained fecal smears (modified Ziehl-Neelsen, safranin methylene blue, auramine phenol), antigen detection (immunofluorescence, enzyme-linked immunosorbent assay or genome detection (polymerase chain reaction amplification of the 18S rRNA gene). Each method varies in sensitivity and specificity and there is no universally accepted 'best method' [8]. Cryptosporidiosis was first described in lambs with diarrhoea in Iran [9], and since then few studies have been carried out to determine the prevalence of cryptosporidial infection in lambs and goat kids $[10,11]$.

This article describes the prevalence of cryptosporidiosis in lambs and goat kids in the Kurdistan province in west of Iran and links its association with various risk factors that include age, sex, and stool consistency.

\section{Materials and Methods}

Ethical approval: Permission was obtained from a local ethics committee acting under guidance from Razi Vaccine and Serum Research Institute, Alborz, Iran.

Sample collection: In this study, 850 and 350 fecal 
Table-1. Frequency of detection of Cryptosporidium spp. oocysts in the fecal samples of lambs

\begin{tabular}{|c|c|c|c|c|c|}
\hline \multirow[t]{3}{*}{ Lambs } & \multicolumn{5}{|c|}{ Oocyst } \\
\hline & \multirow[t]{2}{*}{$\mathrm{n}$} & \multicolumn{2}{|c|}{ Positive } & \multicolumn{2}{|c|}{ Negative } \\
\hline & & $\mathrm{n}$ & $\%$ & $n$ & $\%$ \\
\hline $\begin{array}{l}\text { Diarrhoeic } \\
\text { Non-diarrhoeic } \\
\text { Total }\end{array}$ & $\begin{array}{l}87 \\
763 \\
850\end{array}$ & $\begin{array}{l}56 \\
31\end{array}$ & $\begin{array}{l}64.37 \\
4.06 \\
10.24\end{array}$ & $\begin{array}{l}31 \\
732 \\
763\end{array}$ & $\begin{array}{l}35.63 \\
95.94 \\
89.76\end{array}$ \\
\hline
\end{tabular}

Table-3. Relationship between age and Cryptosporidium spp. oocysts in lambs

\begin{tabular}{lllllll}
\hline Age (Month) & & \multicolumn{3}{c}{ Lambs } \\
\cline { 3 - 4 } & $\mathbf{n}$ & \multicolumn{2}{c}{ Positive } & & \multicolumn{2}{c}{ Negative } \\
\cline { 3 - 4 } \cline { 6 - 7 } & & $\mathbf{n}$ & $\%$ & & $\mathbf{n}$ & $\%$ \\
\hline 1 & 141 & 16 & 11.34 & & 125 & 88.66 \\
2 & 278 & 29 & 10.43 & & 249 & 89.57 \\
3 & 289 & 29 & 10.03 & & 260 & 89.97 \\
4 & 77 & 8 & 9.09 & & 69 & 90.91 \\
5 & 43 & 4 & 9.3 & & 39 & 90.7 \\
6 & 22 & 1 & 4.54 & & 21 & 95.46 \\
Total & 850 & 87 & 10.24 & & 763 & 89.76 \\
\hline
\end{tabular}

samples were collected randomly from lambs and goat kids, respectively. Samples were collected from 48 villages in Kurdistan district, west of Iran. Livestock information was collected by direct observation and by questioning of owners, and included the status of animals as diarrheic and non-diarrheic groups.

Moreover, all the animals in this study were aged 1-6 months. Fecal samples of animals were collected directly from their rectum. The fecal samples were then fixed as quickly as possible in $10 \%$ formalin for preserving until further examination. Moderately thick fecal smears were prepared and air-dried. After fixation by methanol, the fecal smears were stained by modified Ziehl-Neelsen staining. The stained smears were observed under microscope with a $\times 400$ to $\times 1,000$ magnifications. The Cryptosporidium spp. oocysts were visualized as bright red round bodies against a pale green background, containing elongated naked sporozoites. Cryptosporidium infection was scored either positive or negative based on the presence or absence of the oocysts in the examined microscopic fields in each sample. A sample was considered positive for Cryptosporidium spp. if an oocyst was detected bearing the correct morphology, i.e., optical properties, internal structures, size, and shape [3].

Statistical analysis: The results are expressed in percentages. The prevalence for Cryptosporidium was statistically analyzed by the Chi-square test $\left(\chi^{2}\right)$ considering the variables sex, age and stool consistency. The differences were considered statistically significant at $\mathrm{P}<0.05$. SPSS 10.0 for Windows was used to perform the statistical analyses [12].

\section{Results}

The prevalence of Cryptosporidium in lambs and goat kids in Kurdistan province were found to be $10.24 \%$ and $18.86 \%$, respectively. Results show that the prevalence of Cryptosporidium spp. in diarrhoeic
Table-2. Frequency of detection of Cryptosporidium spp. oocysts in the fecal samples of goat kids

\begin{tabular}{lllllll}
\hline Goat kids & & \multicolumn{3}{c}{ Oocyst } \\
\cline { 3 - 4 } & $\mathbf{n}$ & \multicolumn{2}{c}{ Positive } & & \multicolumn{2}{c}{ Negative } \\
\cline { 3 - 4 } \cline { 6 - 7 } & & $\mathbf{n}$ & $\%$ & & $\mathbf{n}$ & $\%$ \\
\hline Diarrhoeic & 59 & 18 & 30.51 & & 41 & 69.49 \\
Non-diarrhoeic & 291 & 48 & 16.49 & & 243 & 85.22 \\
Total & 350 & 66 & 18.86 & & 284 & 81.14 \\
\hline
\end{tabular}

Table-4. Relationship between age and Cryptosporidium spp. oocysts in goat kids

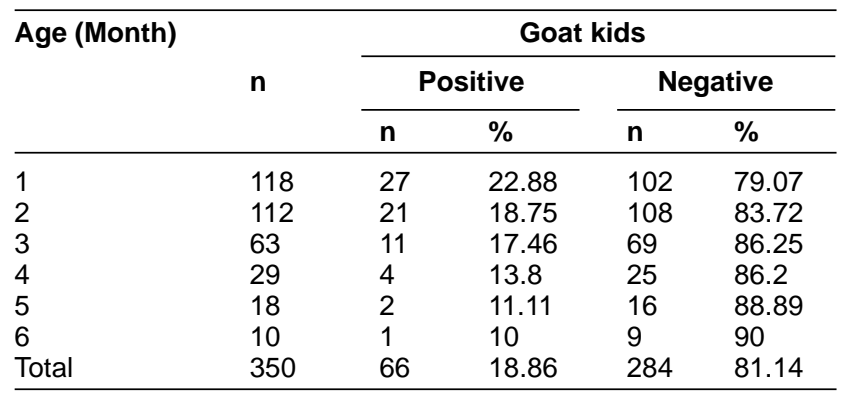

and non-diarrhoeic lambs and goat kids were $64.37 \%$ (56/87), 30.51\% (18/59), $4.06 \%$ (31/763) and $16.49 \%$ $(48 / 291)$, respectively $(P<0.05$; Table- 1 and 2$)$. The prevalence of the infection according to age groups in lambs and goat kids are shown in Table-3 and 4. Infection rates were significantly higher in lambs and goat kids less than 1 month of age $(11.34 \%$ and $22.88 \%)$ than in the remaining age groups $(P<0.05)$, thus the highest risk of being infected with Cryptosporidium in lambs and goat kids is in the first month of their life. Microscopic examination showed that the lambs and goat kids of both sexes were infected with Cryptosporidium: $6.02 \%, 8.32 \%$ of male animals and $4.22 \%$, $10.54 \%$ of female animals were infected. There was no significant difference between prevalence percentages.

\section{Discussion}

In our study, Cryptosporidium oocysts were identified in $12.17 \%$ of the examined samples. Infection rate in lambs was $10.24 \%$, which shows a high infection rate. Also, $18.86 \%$ of goat kids were infected. These results show that the Cryptosporidium infection is present at a high rate in the livestock of Kurdistan region. Similar studies have been carried out in different regions of the country and those studies mostly reported higher prevalence in the similar study groups. For example, $17.2 \%$ in sheep in Lorestan [13], $10.8 \%$ in calves in Isfahan [14] $12.8 \%$ and $2.5 \%$ in calves and goat kids in Hamadan [10], 2\% in dogs in Kerman [15], and 22.6\% infection rate in camels in Yazd [16], respectively.

In other countries, the prevalence was as follows: more than $20 \%$ of fecal samples examined from goats, cows, buffaloes, and sheep were positive for Cryptosporidium in Egypt [17]. In Iraq, similar findings were reported [18]. In Turkey, the prevalence rate in neonatal lambs was $21.05 \%$ [19]. In Europe, Cryptosporidium oocysts were detected in $42.1 \%$ of the examined lambs and 31.8\% goat kids in Serbia [20]. 
In another study, conducted in Romania, the presence of Cryptosporidiosis was observed in $24 \%$ of the goat kids [21]. The differences in the frequency of Cryptosporidium prevalence in lambs and goat kids raised in different geographical regions may be the result of differences in the levels of contamination of the environment with oocysts of the parasite or may be due to differences in the infectivity of different Cryptosporidium spp. populations. It is also possible that the quality of hygienic conditions of animal husbandry and grazing practices may have influenced the exposure of animals to cryptosporidial infection. In this study, we believe that overcrowding the lambs and goat kids together in a small area caused high infection rates.

Some authors suggested that zoonotic transmission is the main mode of trans-mission of Cryptosporidial infection in Iran [22]. Cryptosporidiosis is reported to cause serious problems in young livestock like calves, buffalo calves, lambs and goat kids. Risk factors such as farm management, size of the herd, farm type and hygiene, bedding type, feeding of colostrum, season, diarrhoea, age and contamination sources (e.g. water) play a role in the spread of Cryptosporidium spp. in domestic animals [23-25]. There is no significant relationship between infections and animal sex. Most researchers believe that there is no correlation between the elimination of Cryptosporidium oocysts and the animals' sex [21, 24, 26]. Our results demonstrate that Cryptosporidium is involved in the etiology of diarrhea in lambs and goat kids and that this organism must be considered during the differential diagnosis of enteric infections in lambs and goat kids. Some factors may be related to the overcrowding and the unhygienic conditions under which the animals are housed.

\section{Conclusion}

Our study indicates that the frequency of Cryptosporidium spp. infection in lambs and goat kids in areas of Kurdistan is lower than the other rural areas of Iran.

\section{Authors' contributions}

MK implemented the study design and test samples. OK analyzed the data, drafted and revised the manuscript. Both authors read and approved the final manuscript.

\section{Acknowledgements}

This study was supported with a grant (grant no. 75-0450909119-01) from Razi Vaccine and Serum Research Institute, Kurdistan, Iran.

\section{Competing interests}

The authors declare that they have no competing interests.

\section{References}

1. Carey, C.M., Lee, H. and Trevors, J.T. (2004) Biology, persistence and detection of Cryptosporidium parvum and Cryptosporidium hominis oocyst. Water Res., 38(4):818862.

2. Xiao, L., Fayer, R., Ryan, U. and Upton, S.J. (2004) Crypto- sporidium taxonomy: Recent advances and implications for public health. Clin. Microbiol. Rev., 17:72-97.

3. Fayer, R., Morgan, U., Upton, S.J. (2000) Epidemiology of Cryptosporidium: transmission, detection and identification. Int. J. Parasitol., 30:1305-1322.

4. Barker, I.K. and Carbonell, P.L. (1974) Cryptosporidium bovins sp. $n$. from lambs and Cryptosporidium bovis spp. $\mathrm{n}$. from a calf with observations on the oocyst. Z. Parasitenkd., 44:289-298.

5. Angus, K.W., Appleyard, W.T., Menzies, J.D., Campbell, I. and Sherwood, D. (1982) An outbreak of diarrhea associated with cryptosporidiosis in naturally reared lambs. Vet. Rec., 110:129-130.

6. Snodgrass, D.R., Angus, K.W. and Gray, E.W. (1984) Experimental cryptosporidiosis in germ-free lambs. $J$. Comp. Pathol., 94:141-152.

7. De Graaf, D.C., Vanopdenbosch, E., Ortega-Mora, L.M., Abbassi, H. and Peeters, J.E. (1999) A review of the importance of cryptosporidiosis in farm animals. Int. J. Parasitol., 29:1269-1287.

8. Areeshi, M.Y., Beeching, N.J. and Hart, C.A. (2007) Cryptosporidiosis in Saudi Arabia and neighboring countries. Ann. Saudi Med., 27(5):325-332.

9. Ahourai, P., Ezzi, A., Gholami, M.R., Vandyoosefi, J., Kargar, R. and Maalhagh, N. (1985) Cryptosporidium spp. in new born lambs in Iran. Trop. Anim. Health Prod., 17(1):68.

10. Jafari, R., Maghsood, A.H. and Fallah, M. (2013) Prevalence of Cryptosporidium Infection among Livestock and Humans in Contact with Livestock in Hamadan District, Iran, 2012. J. Res. Health Sci., 13(1):86-89.

11. Vahedi, N., Dalimi Asl, A. and Saadat, M. (2009) Primary research on gastrointestinal cryptosporidium incidence rate in lambs and calves in amol city, Iran. J. Vet. Res., 64(2):101102.

12. SPSS. (2000) SPSS 10.0 for windows student version. http://en.softonic.com/s/spss-10-download. Accessed on 0109-2013.

13. Nouri, M. and Karami, M. (1991) Asymptomatic Cryptosporidiosis in nomadic shepherds and their sheep. $J$. Infect., 23(3):331-333.

14. Azami, M. (2007) Prevalence of Cryptosporidium infection in cattle in Isfahan, Iran. J. Eukaryot Microbiol., 54(1):100-102.

15. Mirzaei, M. (2012) Epidemiological survey of Cryptosporidium spp. in companion and stray dogs in Kerman, Iran. Vet. Ital., 48(3):291-296.

16. Sazmand, A., Rasooli, A., Nouri, M., Hamidinejat, H. and Hekmatimoghaddam, S. (2012) Prevalence of Cryptosporidium spp. in camels and involved people in Yazd Province, Iran. Iranian J. Parasitol., 7(1):80-84.

17. Shoukry, N.M., Dawoud, H.A. and Haridy, F.M. (2009) Studies on zoonotic Cryptosporidiosis parvum in Ismailia Governorate, Egypt. J. Egypt Soc. Parasitol., 39:479-488.

18. Al-Dabbagh, N.Y., Abbassa, E.T. and Ahmed, M.M. (2010) Evaluation of risk factors of cryptosporidiosis in children: a case-control study in Mosul city. Tikrit Med. J., 16:73-79.

19. Gokce, E., Ünver, A. and Erdogan, H.M. (2010) Enteric Pathogens in the etiology of Diarrhoea in Neonatal Lambs. Kafkas Univ.Vet. Fak.Derg., 16(5):717-722.

20. Misic, Z., Katic-Radivojevic, S. and Kulisic, Z. (2006) Cryptosporidium infection in lambs and goat kids in Serbia. Acta Veterinaria., 56(2-3):49-54.

21. Bejan, A., Mircean, V., Radu, C., Smaro, S. and Cozma, V. (2009) Epidemiology of Cryptosporidium spp. infection in goat kids in the central and the northwest part of Romania. Sci. Parasitol., 1:32-36.

22. Mojarad, N.H.E., Keshavarz, A., Taghipour, N., Haghighi, A., Kazemi, B. and Athari, A. (2011) Genotyping of Cryptosporidium spp. in clinical samples: PCR-RFLP analysis of the TRAP-C2 gene. Gastroenterology and Hepatology from Bed to Bench., 4(1):29-33.

23. Brook, E., Hart, C.A., French, N. and Christley, R. (2008) 
Prevalence and risk factors for Cryptosporidium spp. infection in young calves. Vet. Parasitol., 152:46-52.

24. Delafossa, A., Castro-Hermida, J.A., Baudry, C., AresMazas, E. and Chartier, C. (2006) Herd-level risk factors for Cryptosporidium infection in dairy-goat kids in western France. Pre. Vet. Med., 77(1-2):109-121.

25. El-Khodery, S.A. and Osman, S.A. (2008) Cryptosporidiosis in buffalo calves (Bubalus bubalis): Prevalence and potential risk factors. Trop. Anim. Health Prod., 40(6):419-426.

26. Noordeen, F., Rajapakse, R.P., Faizal, A.C., Horadagoda, N.U. and Arulkanthan, A. (2000) Prevalence of Cryptosporidium infection in goats in selected locations in three agroclimatic zones of Sri Lanka. Vet. Parasitol., 93(2):95101.

\section{$* * * * * * * *$}

